\title{
European Speed Environment Model for Highway Design-Consistency
}

\author{
Gianluca Dell'Acqua ${ }^{1}$ \\ ${ }^{1}$ Department of Transportation Engineering “Luigi Tocchetti”, University of Napoli “Federico II”, Napoli, Italy \\ Correspondence: Gianluca Dell'Acqua, Department of Transportation Engineering "Luigi Tocchetti”, University \\ of Napoli "Federico II", Via Claudio 21, Napoli I-80125, Italy. Tel: 39-8-1768-3934. E-mail: \\ gianluca.dellacqua@unina.it
}

Received: June 16, $2012 \quad$ Accepted: August 12, $2012 \quad$ Online Published: August 17, 2012
doi:10.5539/mas.v6n9p1
URL: http://dx.doi.org/10.5539/mas.v6n9p1

\begin{abstract}
The European road network is very large, and much of it is made up of two-lane rural roads. In Italy the road network requires adjustment work to improve mobility safety management. One of the most important tools for this analysis is the operating speed $\left(V_{85}\right)$ profile. In many design standards, different formulations are used for estimating $V_{85}$, obtained on the basis of research carried out at different times and in different contexts. The aim of the research presented in this study is to analyze driver speed behavior on two-lane rural highways. The study was conducted using traffic counters, able to record in both directions and for every passage of a vehicle, its length, instant speed and direction. The survey plan was elaborated to satisfy different research objectives. The readings were taken by keeping every section under observation for 3, 6 or 12 hours. The data were collected on 11 homogeneous sections of highway. The database consisted of free-flow passenger car speeds and various geometric data from 103 sites. Data were collected at sites to both develop and validate equations. The proposed model includes the radius of horizontal curvature and the "Speed Environment", which is defined as the speed at which users travel in free-flow conditions when they are not constrained by the alignment of the highway.
\end{abstract}

Keywords: "Speed Environment", validation, design consistency, rural highways, driver behavior

\section{Introduction}

The safety performance of existing highways should be increased by targeting investments towards the highest accident concentration sections (Brewer et al., 2001) and to the highway sections with the highest accident reduction potential (Jasiūniene et al., 2012). In fact crashes are often due to bad decisions by drivers made in environments created by engineers (Dell'Acqua, 2011). International research (Esposito et al., 2011) has thus suggested a variety of approaches to analyze the road traffic safety level on the basis of an assessment of accident rates and frequency (Discetti et al., 2011). Road traffic safety has since become a worldwide priority and one of the major factors for a description of the state of the traffic system in terms of both positive and negative changes (De Luca et al., 2011). Many researchers have shown that one of the parameters that most influence safe driving is the speed variable, and in the literature some research work has dealt with speed prediction models to analyze real driver behavior (Dell'Acqua \& Russo, 2011a). The experimental analysis presented here is only one component of a larger study which has been under way on a number of roads for several years now with a view to improving performance, road management and safety (Dell'Acqua et al., 2011a-b-c). Moreover, many models are used as a quantitative tool for the evaluation of the impact of design consistency on road safety ( $\mathrm{Ng}$ et al., 2004). Regarding two-lane rural roads, researchers from all over the world have attempted to overcome the problems that prevent the formulation of a prediction model for operating speeds. These models are fairly exhaustive, examining driver speed behavior on tangents, curves and spiral transitions. They aim to reach formulations that can correlate operating speeds and the principal geometric features of the elements themselves. Polus et al. (2000) developed, for example, a model to predict operating speeds on tangent segments. The sites were divided into four groups based on the tangent length and the preceding and following radii of the horizontal curves. Later, Fitzpatrick et al. (2003) collected speed and geometric data in 78 sites and speed models for which five different highway classes were developed. Rereading the scientific literature on a critical note, the first approach to the study followed the search for a speed representative of drivers' behavior on whole road sections, including those of a certain length, with similar 
geometric features. Subsequently, identifying proper new parameters to be used as independent variables for operating speeds led researchers to seek any correlation between the operating speeds maintained on a single section and the most important geometric characteristics of the elements themselves. Some studies have shown how acceleration and deceleration actions occurred only on tangent segments and a constant speed was, subsequently, maintained by drivers on circular elements (Ottesen et al., 2000). A complete speed-profile was studied for example by Figueroa-Medina and Tarko (2004). They subsequently calibrated predictive speed models on tangents and curves which are not restricted to a specific percentile, but for all percentile speeds from the $5^{\text {th }}$ to the $95^{\text {th }}$ in increments of five. In a recent study, an extension to the speed-profile model was developed to incorporate the effect of sight obstruction on operating speeds and deceleration rates (Easa, 2003).

\section{Experimental Analysis}

There were two main components to data collection: the geometric features of the alignment, and the operating speeds. The data set was dividing in two parts, the first one was used to develop the model and the second was employed to validate it. General criteria were used to select sites that represent the common conditions found along Italian highways (Table 1). The traffic never exceeded 400 vehicles/hour during data collection.

The alignments of the highways (Figure 1) are without spiral transition curves. The survey stations were located on geometric elements with constant curvature in free flow conditions. The selected infrastructures (Figure 2) for the survey are all located in areas with level terrain, and the road vertical slope is by far inferior to $\pm 4 \%$ (Dell'Acqua \& Russo, 2011b).

Table 1. Site selection criteria

\begin{tabular}{ll}
\hline Control & Criteria \\
\hline Area Type & Rural \\
Functional Classification & minor arterial \\
Posted Speed Limit & $50 \mathrm{~km} / \mathrm{h}$ to $90 \mathrm{~km} / \mathrm{h}$ \\
Terrain & Level \\
Radii & $50 \mathrm{~m}$ to $2200 \mathrm{~m}$ \\
Grade & $-4 \%$ to $+4 \%$ \\
Traffic Volumes & $\leq 100$ vehicles per hour \\
Carriageways Widths & $5 \mathrm{~m}$ to $12 \mathrm{~m}$ \\
Tangent Length & No restrictions \\
\hline
\end{tabular}

The geometric features of each section were obtained from the Regional Territorial Cartography Bureau (Figure 3). For the purpose of this research, three laser traffic counters were used. These devices have two photocells for the emission and reception of a pair of laser beams perpendicularly directed to the road axis. Vehicle speed is inferred from the movement of the vehicle from the first photocell to the second.

The measurer was lodged in a fixed posting. The devices recorded time, vehicle speed, length of vehicle, and direction of travel for each vehicle passing. The data were filtered to get a sample of transits truly representative of the passage of cars in free-flow conditions, because the "Speed Environment" is more feasible on "faster" layouts, and the operating speeds necessarily refer to low traffic conditions.

The transits of vehicles were enucleated with: length between 2.5 and 9.0 meters, such as cars for private use; gap superior to 5 seconds after the preceding vehicle (to free the results from conditioning by the previous vehicle). The highways were selected according to the following criteria: the high maximum value of the recorded operating speed $\left(V_{85}>60 \mathrm{~km} / \mathrm{h}\right)$, the index of the probability of reaching the "Speed Environment" $\left(V_{e n v}\right)$ defined as "the speed at which drivers choose to travel under free-flow conditions when they are not constrained by alignment features" (Austroads, 2009); the traffic flow related to the whole period of the study. The flow rate was always below 400 vehicles/h. In the preliminary analysis, scatter plots and correlation matrices were used to recognize potential links between the radius, the "Speed Environment" and the operating speed. Then the variables with a higher explanatory value were identified by performing a linear regression analysis. One of these is the curvature change rate of a single curve (CCRs):

$$
C C R s=(200 / \pi)[L 2 / R+(L 1+L 3) / 2 R] / L \quad[g o n / k m]
$$



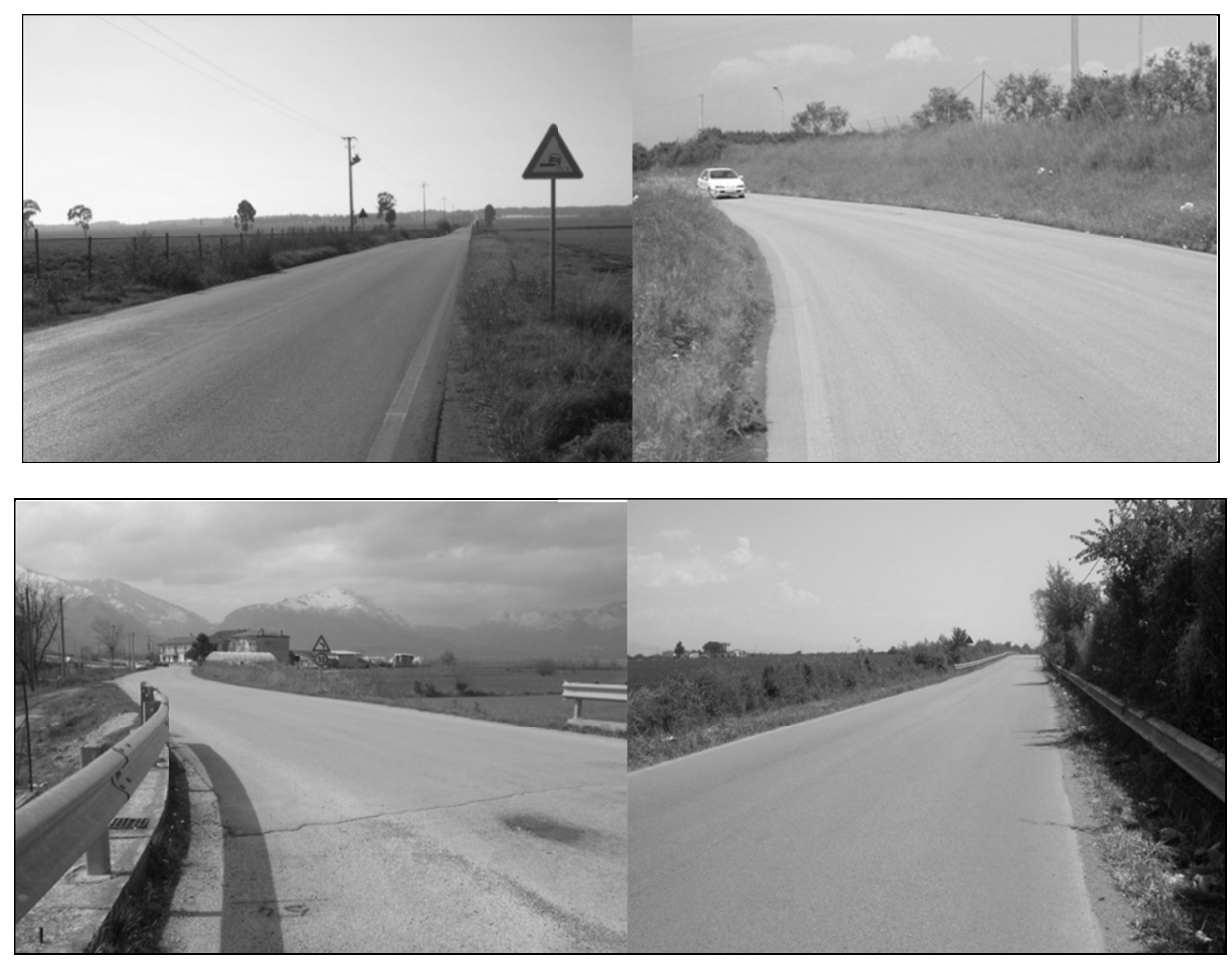

Figure 1. Provincial highways SP 30b, SP 312, SP 52 and SP 262
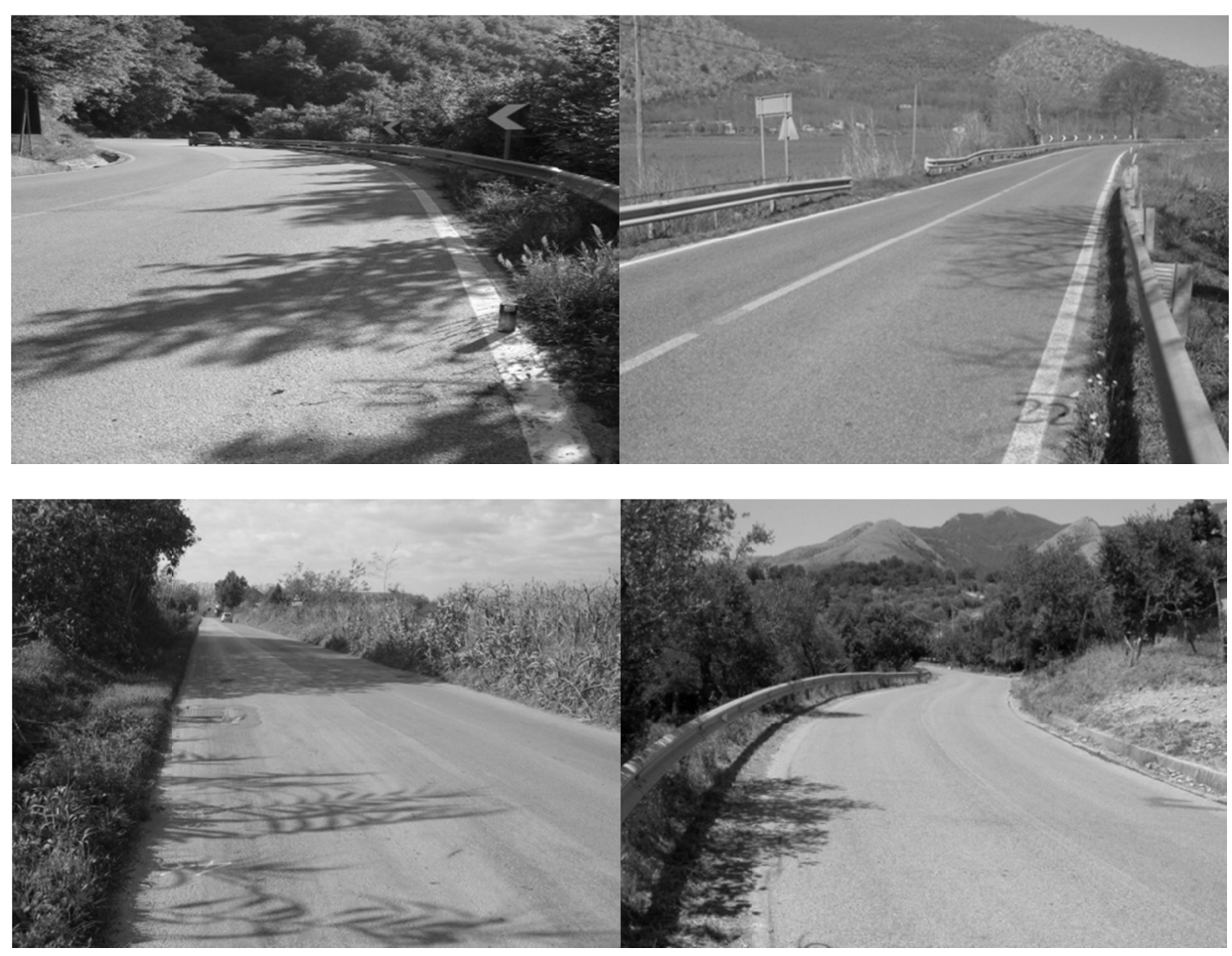

Figure 2. State highways SS 426, SS 103, SS 166 and Provincial highway SP 135 


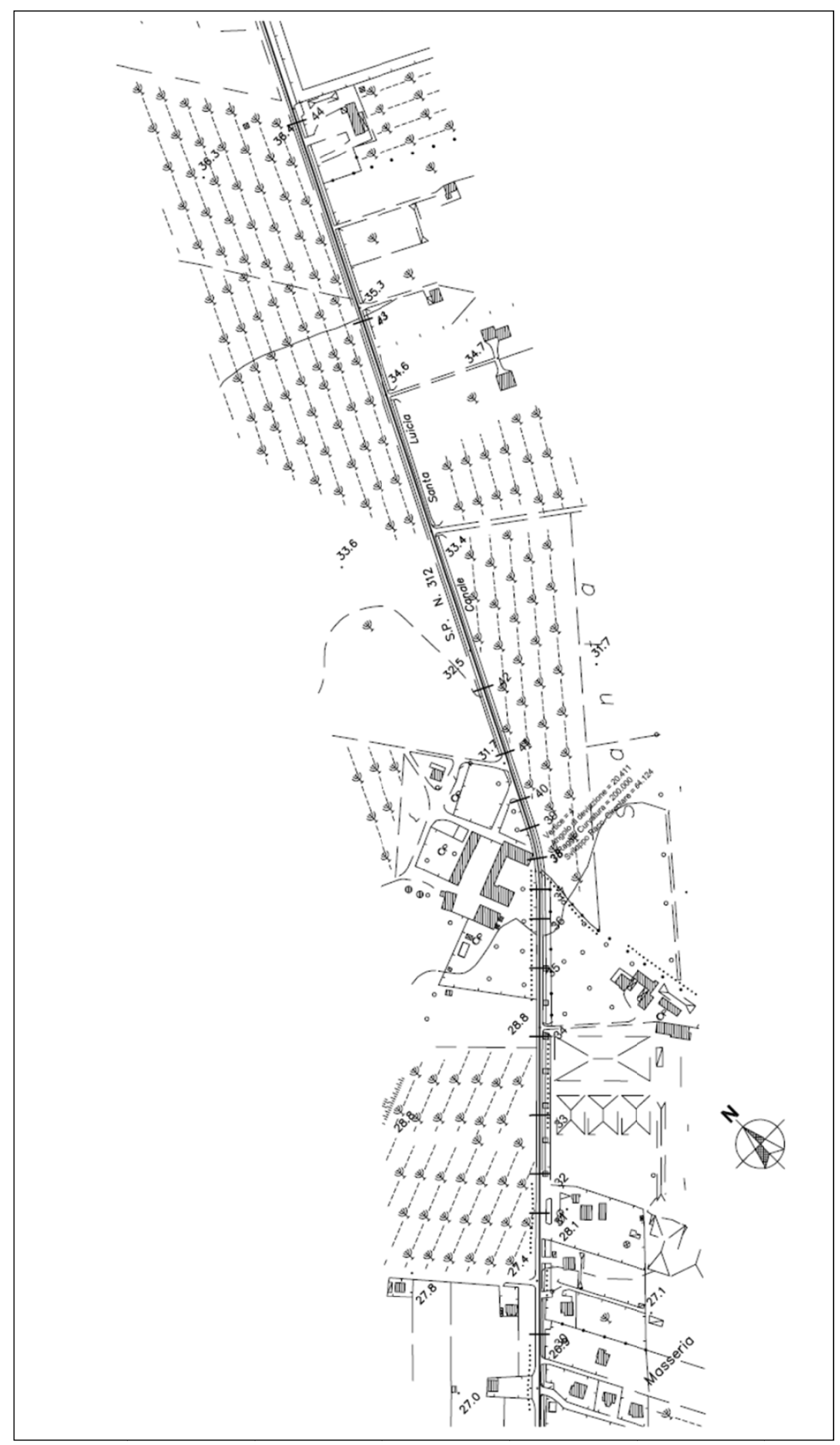

Figure 3. Rural highway SP 312 alignment 
$L_{1}$ and $L_{3}$ are spiral transition lengths, $L_{2}$ is the length of the circular curve and $L=L_{1}+L_{3}+L_{2}$, while $R$ is the radius of the curve. Operating speed decreases as the degree of curvature increases and speed decreases as the radius is reduced (Figure 4). The Kolmogorov-Smirnov test results indicated that at many of the sites, speeds did follow a normal distribution.

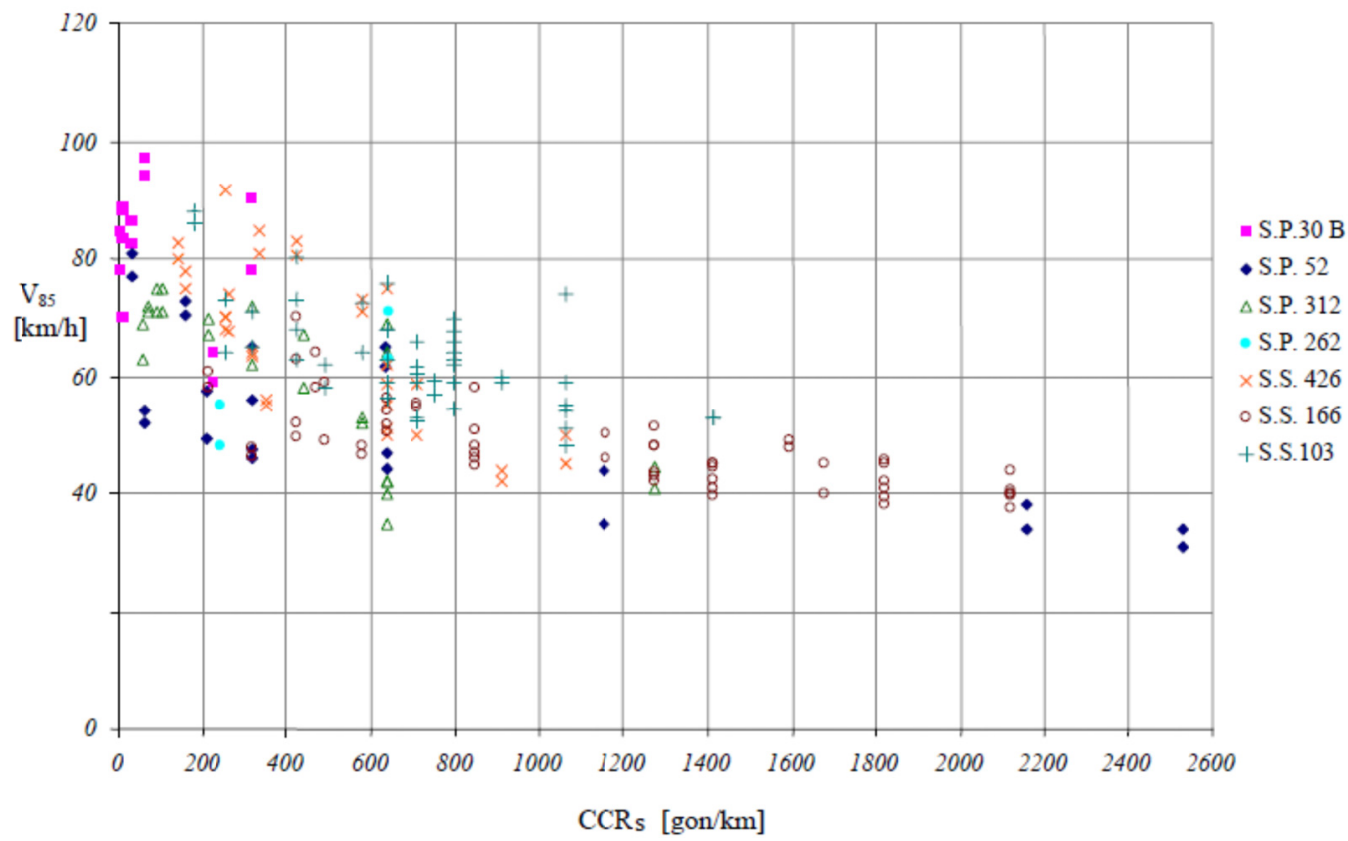

Figure 4. Curves: observed $85^{\text {th }}$ percentile versus CCRs

The analysis shows that the inverse of the square root of the radius correlates well to the $85^{\text {th }}$ percentile speed:

$$
\begin{array}{lll}
V_{85 c} & =74.88-0.02 C C R_{s}[\mathrm{~km} / \mathrm{h}] & r^{2}=0.58 \\
V_{85 c}=87.31-272.54 /(R)^{1 / 2}[\mathrm{~km} / \mathrm{h}] & r^{2}=0.60
\end{array}
$$

In the next step, the geometric parameters of the individual elements examined (curvature radius, longitudinal and transversal slope, width of carriageway, etc.) were added to the variables (such as "Speed Environment", $\left.V_{e n v}\right)$ of the homogeneous road section to which the element belongs. This approach provides the most accurate models, with greater regression coefficients. However there is the difficulty of identifying proper criteria to divide the alignment into homogeneous sections and to determine the $V_{\text {env }}$.

The study also analyzed the relationship between the operating speed on curves and the independent Curvature Change Rate $(C C R)$ variable of the road section to which the curve belonges (Table 2). According to German design standards (FGSV, 1998), the $C C R$ is the sum of the angular changes in the horizontal alignment divided by the length of the homogeneous road section (Figure 5). The equations were considered unsatisfactory for the development of an operating speed profile so another approach was investigated.

\section{Model Development and Results}

"Speed Environment" is defined as the maximum $85^{\text {th }}$ percentile value of the speeds surveyed on long tangents or very large radius curves belonging to a homogeneous road section (Cox \& Arndt, 2010). The proposed equation includes the radius $(R)$ of curves and the "Speed Environment" $\left(V_{e n v}\right)$. The best model (Table 3$)$ is the following Equation (4), as may be seen in Table 4. This equation can be used for $R<2000 \mathrm{~m}$, but when $R>2000$ $\mathrm{m}, V_{85 c}=V_{e n v}$. Moreover, the "Speed Environment" $\left(V_{e n v}\right)$ had a statistically significant correlation to $V_{85 c}$ :

$$
V_{85 c}=46.47+0.35 \cdot V_{e n v}-1678.12 \cdot(1 / R)+22013.83 \cdot(1 / R)^{2}[\mathrm{~km} / \mathrm{h}] \quad r^{2}=0.64
$$




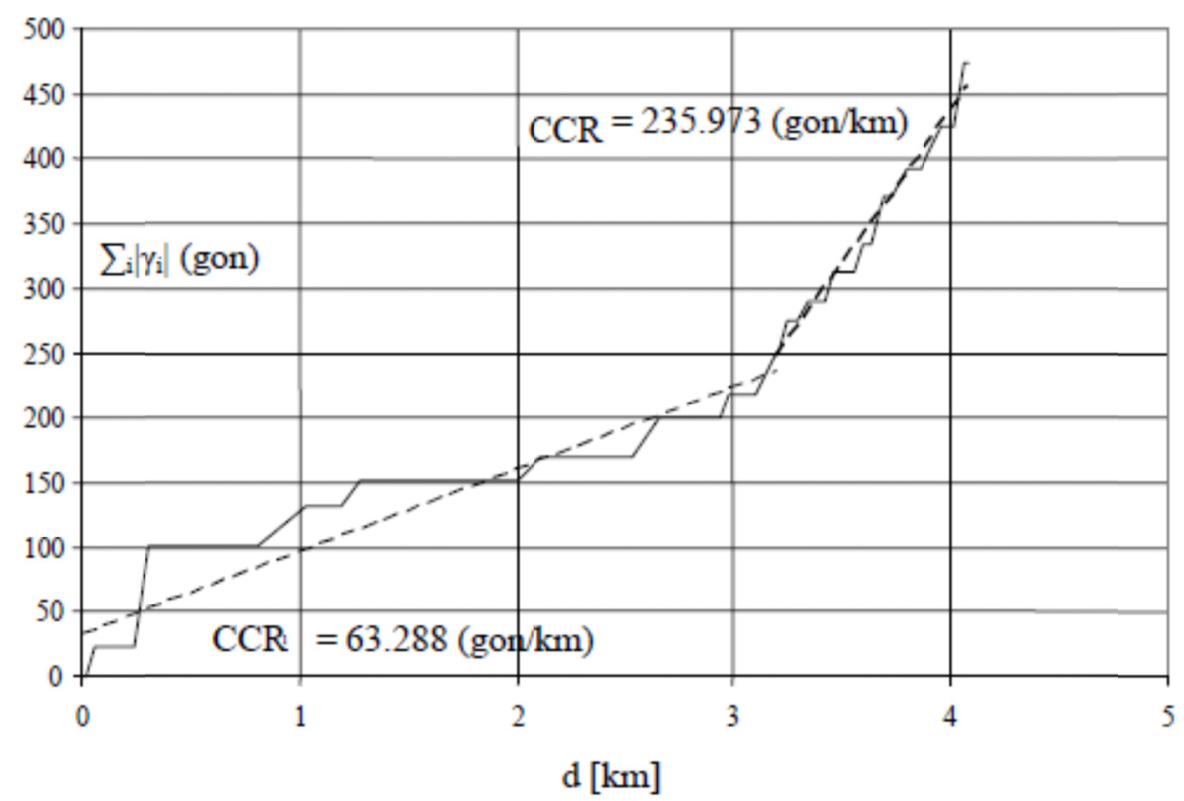

Figure 5. CCR for the State highway SS426

Table 2. Speed prediction models using CCR

\begin{tabular}{ccccc}
\hline $\begin{array}{c}C C R=\sum_{i}\left|\gamma_{i}\right| / d \\
{[\text { gon } / \mathrm{km}]}\end{array}$ & $\begin{array}{c}V_{\text {env }} \\
{[\mathrm{km} / \mathrm{h}]}\end{array}$ & $\begin{array}{c}\text { Number } \\
\text { of sites }\end{array}$ & $\begin{array}{c}V_{85 c} \\
{[\mathrm{~km} / \mathrm{h}]}\end{array}$ & $\rho^{2}$ \\
\hline$<30$ & $97.15 \div 102.65$ & 8 & $V_{85 c}=85.62-\frac{180.26}{\sqrt{R}}$ & 0.21 \\
$30 \div 80$ & $87.9 \div 96$ & 44 & $V_{85 c}=87.74-\frac{268,17}{\sqrt{R}}$ & 0.46 \\
$80 \div 160$ & 86.45 & 8 & $V_{85 c}=87.14-\frac{211.09}{\sqrt{R}}$ & 0.44 \\
$>160$ & $63 \div 95$ & 108 & $V_{85 c}=82.36-\frac{235.70}{\sqrt{R}}$ & 0.47
\end{tabular}

Table 3. Estimation parameters (Equation 4)

$$
\text { Model is: } \mathrm{v}_{1}=\mathrm{a}_{0}+\mathrm{a}_{1} \cdot \mathrm{v}_{1}+\mathrm{a}_{2} \cdot\left(1 / \mathrm{v}_{2}\right)+\mathrm{a}_{3} \cdot\left(1 / \mathrm{v}_{3}\right)^{2}
$$

Dep. Var.: $\mathrm{V}_{85 \mathrm{c}}[\mathrm{km} / \mathrm{h}] \quad$ Level of confidence: $95.0 \%$ (alpha=0.050)

\begin{tabular}{ccccccc}
\hline & Estimate & $\begin{array}{c}\text { Standard } \\
\text { Error }\end{array}$ & $\begin{array}{c}\mathrm{t} \text {-value } \\
\mathrm{df}=100\end{array}$ & p-level & $\begin{array}{c}\text { Lo. Conf } \\
\text { Limit }\end{array}$ & $\begin{array}{c}\text { Up. Conf } \\
\text { Limit }\end{array}$ \\
\hline $\mathrm{a}_{0}$ & 46.47 & 7.38 & 6.30019 & 0.000000 & 31.90 & 61.03 \\
$\mathrm{a}_{1}$ & 0.35 & 0.08 & 4.45874 & 0.000016 & 0.19 & 0.50 \\
$\mathrm{a}_{2}$ & -1678.12 & 300.73 & -5.58007 & 0.000000 & -2272.16 & -1084.08 \\
$\mathrm{a}_{3}$ & 22013.83 & 10159.41 & 2.16684 & 0.031764 & 1946.07 & 42081.59 \\
\hline
\end{tabular}


Table 4. Model comparison

\begin{tabular}{|c|c|c|c|c|c|c|c|c|c|}
\hline \multirow{2}{*}{ Equation } & \multicolumn{4}{|c|}{ Parameters } & \multirow{2}{*}{$\rho^{2}$} & \multicolumn{4}{|c|}{ p-level } \\
\hline & $a_{0}$ & $a_{1}$ & $a_{2}$ & $a_{3}$ & & $\mathrm{p}_{0}$ & $\mathrm{p}_{1}$ & $\mathrm{p}_{2}$ & $\mathrm{p}_{3}$ \\
\hline $\mathrm{V}_{85}=\mathrm{a}_{0}+\mathrm{a}_{1} \cdot \mathrm{CCR}_{\mathrm{s}}$ & 74.88 & -0.020 & - & - & 0.58 & 0.000 & 0.000 & - & - \\
\hline $\mathrm{V}_{85}=\mathrm{V}_{\text {env }} /\left(1+\mathrm{a}_{0} / \mathrm{R}^{\mathrm{a} 1}\right)$ & 3.47 & 0.48 & - & - & 0.57 & 0.000 & 0.000 & - & - \\
\hline \multirow{4}{*}{$\mathrm{V}_{85}=\mathrm{a}_{0}+\mathrm{a}_{1} / \mathrm{R}^{0.5}$} & 85.62 & -180.26 & - & - & 0.21 & 0.000 & 0.252 & - & - \\
\hline & 87.74 & -268.17 & - & - & 0.46 & 0.000 & 0.000 & - & - \\
\hline & 87.14 & -211.09 & - & - & 0.44 & 0.000 & 0.073 & - & - \\
\hline & 82.36 & -235.70 & - & - & 0.47 & 0.000 & 0,000 & - & - \\
\hline $\mathrm{V}_{85}=\mathrm{a}_{0}+\mathrm{a}_{1} / \mathrm{R}+\mathrm{a}_{2} / \mathrm{R}^{2}+\mathrm{a}_{3} \cdot \mathrm{V}_{\text {env }}$ & 46.47 & -1678.12 & 22013.83 & 0.35 & 0.64 & 0.000 & 0.000 & 0.000 & 0.000 \\
\hline
\end{tabular}

The regression equation has one independent variable: the curvature change rate CCR (gon $/ \mathrm{km})$. The regression parameter of the analysis is statistically significant $(\mathrm{P}$-value $<0.05)$ for the collected data (Table 5):

$$
V_{\text {env }}=97.49-0.05 \mathrm{CCR}[\mathrm{km} / \mathrm{h}] \quad r^{2}=0.84
$$

Table 5. "Speed Environment" model estimation parameters

$$
\text { Model: } \mathrm{V}_{\mathrm{env}}=\mathrm{a}_{0}+\mathrm{a}_{1} \cdot \mathrm{CCR}
$$

Dep. Var. : $\mathrm{V}_{\text {env }}[\mathrm{km} / \mathrm{h}]$ Level of confidence: $95.0 \%$ ( alpha=0.050)

\begin{tabular}{ccccccc}
\hline & Estimate & $\begin{array}{c}\text { Standard } \\
\text { Error }\end{array}$ & $\begin{array}{c}\text { t-value } \\
\mathrm{df}=9\end{array}$ & $\mathrm{p}$-level & $\begin{array}{c}\text { Lo. Conf } \\
\text { Limit }\end{array}$ & $\begin{array}{c}\text { Up. Conf } \\
\text { Limit }\end{array}$ \\
\hline $\mathrm{a}_{0}$ & 97.49169 & 2.231751 & 43.68395 & 0.000000 & 92.44312 & 102.5403 \\
$\mathrm{a}_{1}$ & -0.05363 & 0.007897 & -6.79124 & 0.000080 & -0.07150 & -0.0358 \\
\hline
\end{tabular}

Speeds on a tangent increase with the "Speed Environment" and depend on tangent length and the operating speed of the preceding curve. If the tangent length is greater than 750 meters, the operating speed on the tangent is equal to the "Speed Environment" of the homogeneous section to which the tangent section belongs; while if the tangent length is smaller than 750 meters the operating speed on tangents can be estimated using Equation (4) with $1 / \mathrm{R}=0$. The next step was a validation analysis to evaluate the accuracy with which the equations predict the operating speeds. The validation data set consists of speeds not included in the model development data set, recorded on curves (radii: 150, 220, 250, 300 and 320 meters) on the SP 135 rural highway. To determine the accuracy of the equation, the mean absolute deviation $(M D A)$, the mean squared error (MSE) and the validation index $(I)$ for the Equation (4) were calculated across all validation sites. The results are presented in Table 6 . The low values of $M A D, M S E$ and $I$ indicate the effectiveness of the model being due to the reduced gap between the observed results and the forecasts. The calculated value of the validation index $(I)$ was:

$$
I=\frac{\sqrt{\sum \frac{\left(Y_{i}-Y_{i}\right)^{2}}{n}}}{\sum \frac{Y_{i}}{n}}=0.08
$$

The control chart, however, highlights specific forecasting errors. The error estimate is a random residual normally distributed with a mean of zero and a standard deviation of $\sigma$ (Figure 6). This result makes it possible to extend the properties of a normal variable to the examined characteristics, as reported in the calculation tables. By setting a level of confidence of $95 \%$ for the measurements identified, the forecast is considered "good" if $95 \%$ of the observed data present an error of $\pm 2 \sigma$.

The calculated value of $\sigma$ was: 


$$
\sigma=\sqrt{M S E}=\sqrt{34.3}=5.86 \quad[\mathrm{~km} / \mathrm{h}]
$$

Since all the errors of estimates range from $-2 \sigma$ to $+2 \sigma$, the results can be considered positive, as confirmed by the validation index $(I)$ which estimates the relationship between the deviation and the expected value rating observations (Figure 7).

Table 6. Deviations, MAD, MSE

\begin{tabular}{cccccc}
\hline & $\begin{array}{c}\text { Observed } \\
85^{\text {th }} \\
\text { percentile }\end{array}$ & Predicted & Error & Absolute Error & Squared error \\
\hline $\mathrm{i}$ & $\mathrm{Yi}$ & $\underline{\mathrm{Yi}}$ & $\mathrm{Di}=\underline{\mathrm{Yi}}-\mathrm{Yi}$ & $|\mathrm{Di}|=\mid \underline{\mathrm{Yi}-\mathrm{Yi} \mid}$ & $\mid \underline{\mathrm{Yi}-\left.\mathrm{Yi}\right|^{\wedge} 2}$ \\
1 & 66.00 & 67.76 & 1.8 & 1.8 & 3.10 \\
2 & 70.00 & 71.61 & 1.6 & 1.6 & 2.59 \\
3 & 82.00 & 72.94 & -9.1 & 9.1 & 82.07 \\
4 & 69.00 & 74.70 & 5.7 & 5.7 & 32.51 \\
5 & 76.00 & 67.76 & -8.2 & 8.2 & 67.88 \\
6 & 76.00 & 71.61 & -4.4 & 4.4 & 19.27 \\
7 & 81.00 & 72.94 & -8.1 & 8.1 & 64.95 \\
8 & 73.30 & 74.70 & 1.4 & 1.4 & 1.97 \\
\hline & & & & $\mathrm{MAD}=5.0$ & $\mathrm{MSE}=34.3$ \\
\hline
\end{tabular}

\section{Conclusions}

The two-lane rural highways represent the greater part of the Italian road network. Experimental evidence has confirmed that the speeds adopted by the drivers using them are not consistent with the road design standards and with the imposed legal speed limits. The high dispersion of the speed distributions is an indicator that the drivers are scarcely conditioned by the layout in their driving choice behavior. The models developed to estimate the operating speed $\mathrm{V}_{85}$ show very good prediction ability after introducing the "Speed Environment".

The models, calibrated using an ample experimental casuistry, are representative of the real flow conditions on the territory in question and, at the same time, are of immediate applicability by the highway administrations. Designers should use the models for the assessment and upgrading of existing roads and the design of new roads. The speed models require an iterative approach to road design and applying it correctly will give good results.

The validation of the speed-prediction equation for horizontal curves was performed by comparing the predicted equation $V_{85}$ with the observed field, $V_{85}$ at the midpoint of the curve. The mean absolute deviation error for the equation was $5.0 \mathrm{Km} / \mathrm{h}$. The "Speed Environment" model $V_{\text {env }}$ proposed uses the curvature change rate of the homogeneous section as independent variables and shows very good prediction ability. Some limitations are:

- the subjective determination of road sections, as it is not always obvious where a change occurs, but proper use of the model will usually result in insignificant differences;

- $\quad$ secondary factors are not taken into account (for example: road function, slope, etc.). 


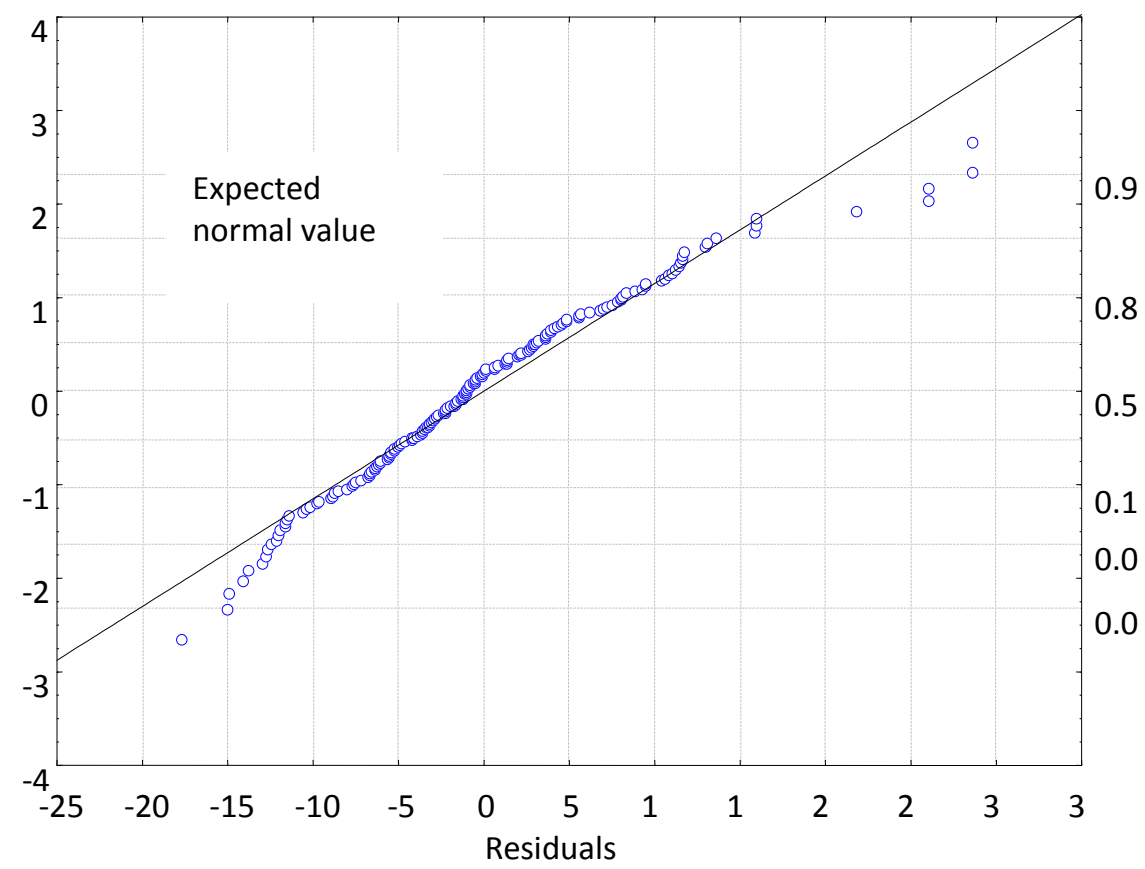

Figure 6. Half-normal probabilistic plot of residuals

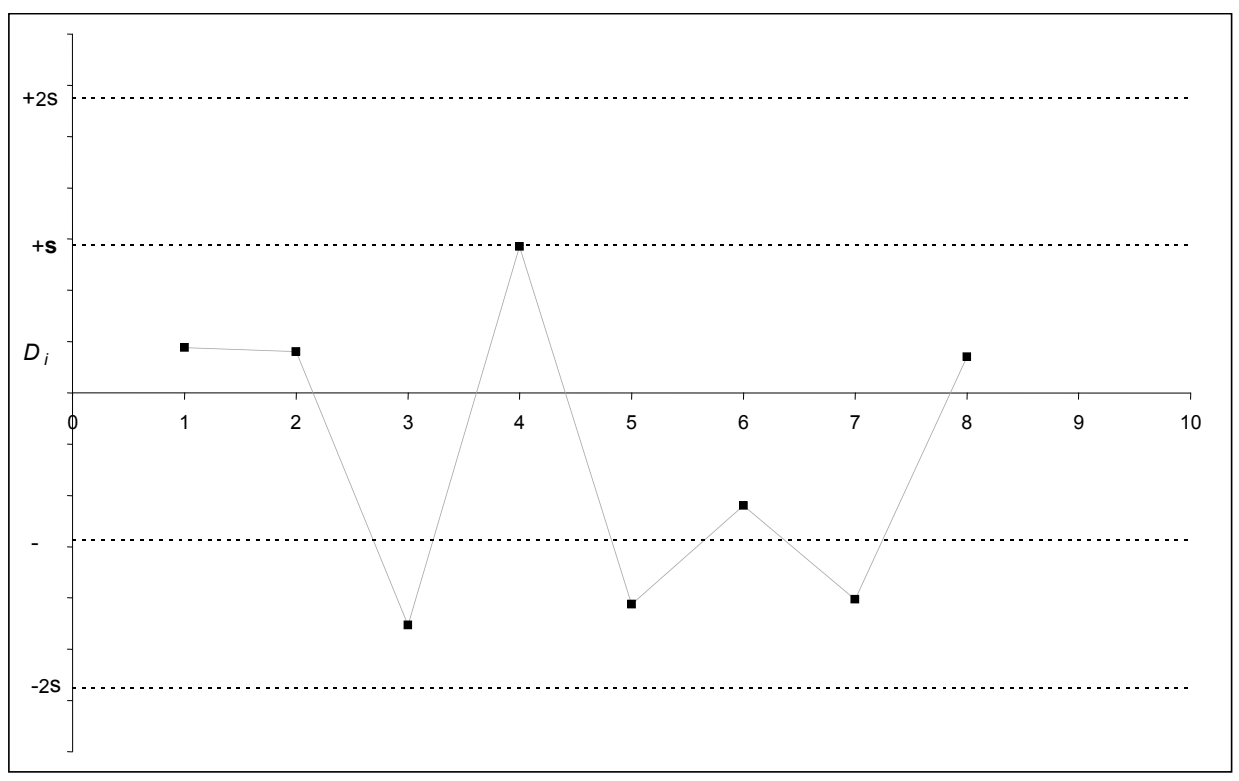

Figure 7. Control chart

\section{Acknowledgements}

The research was conducted as part of the Italian National Research Project 2008 "Driver speed behaviour evaluation using operating speed profile and accident predicting models".

\section{References}

Brewer, J., German, J., Krammes, R., Movassaghi, K, Okamoto, J., Otto, S., ... Walters, R. (2001). Geometric Design Practices for European Roads. Federal Highway Administration. Report No. FHWA-PL-01-026.

Cox, R. L., \& Arndt, O. K. (2010). Australian Experience with using Speed Prediction Models to determine accurate Design Speeds. Proccedings of the $4^{\text {th }}$ International Symposium on Highway Geometric Design. 
Dell'Acqua, G. (2011). Reducing Traffic Injuries Resulting from Excess Speed: Low-Cost Gateway Treatments in Italy. Transportation Research Record: Journal of the Transportations Research Board, 2203, 94-99. http://dx.doi.org/10.3141/2203-12

Dell'Acqua, G., De Luca, M., \& Lamberti, R. (2011a). Indirect Skid resistance Measurement for Porous asphalt Pavement Management. Transportation Research Record: Journal of the Transportations Research Board, 3(2205), 49-58. http://dx.doi.org/10.3141/2205-19

Dell'Acqua, G., De Luca, M., Mauro, R., \& Lamberti, R. (2011b). Motorway Speed Management in Southern $\begin{array}{lllll}\text { Italy. Procedia: Social \& Behavioral } & \text { Sciences, } & \text { 20/2011, } & 49-58 .\end{array}$ http://dx.doi.org/10.1016/j.sbspro.2011.08.010

Dell'Acqua, G., De Luca, M., \& Mauro, R. (2011c). Road Safety Knowledge-Based Decision Support System. Procedia: Social \& Behavioral Sciences, 20, 973-983. http://dx.doi.org/10.1016/j.sbspro.2011.08.106

Dell'Acqua, G., \& Russo, F. (2011a). Road Performance Evaluation Using Geometric Consistency and Pavement Distress Data. Transportation Research Record: Journal of the Transportations Research Board, 2203, 194-202. http://dx.doi.org/10.3141/2203-24

Dell'Acqua, G., \& Russo, F. (2011b). Safety Performance Functions for Low-Volume Roads. The Baltic Journal of Road and Bridge Engineering, 6(4), 225-234. http://dx.doi.org/10.3846/bjrbe.2011.29

De Luca, M., Mauro, R., Russo, F., \& Dell'Acqua, G. (2011). Before-After Freeway Accident Analysis using Cluster Algorithms. Procedia: Social \& Behavioral Sciences, 20/2011, 723-731. http://dx.doi.org/10.1016/j.sbspro.2011.08.080

Discetti, P., Dell'Acqua, G., \& Lamberti. R. (2011). Models of Operating Speeds for Low-volume Roads. Transportation Research Record: Journal of the Transportations Research Board, 2203, 219-225. http://dx.doi.org/10.3141/2203-27

Easa, S. M. (2003). Improved speed-profile model for two-lane rural highways. Canadian Journal of Civil Engineering, 30(6), 1055-1065.

Esposito, T., Mauro, R., Russo, F., \& Dell'Acqua, G. (2011). Speed prediction models for sustainable road safety management. Procedia: Social \& Behavioral Sciences, 20/2011, 568-576. http://dx.doi.org/10.1016/j.sbspro.2011.08.063

Figueroa Medina, A. M., \& Tarko, A. P. (2005). Speed Factors on Two-Lane Rural Highways in Free-Flow Conditions. Transportation Research Record: Journal of the Transportation Research Record, 1912, 39-46.

Fitzpatrick, K., Carlson, P., Brewer, M., Wooldridge, M., \& Miaou, S. (2003). Design Speed, Operating Speed and Posted Speed Practices. Retrieved from http://onlinepubs.trb.org/onlinepubs/nchrp_wrpt_504.pdf

Forschungsgesellgesahftfur Strassen und Verkehrswesen (FGSV) (1998). Guidelines for the Construction of Roads, Part: Manual for the Functional Structuring of the Road System, RAS-N, Kirschbaum Verlag, Bonn, Germany.

Guide to Road Design (Part 3). (1998). Austroads, Sydney, Australia.

Jasiūnienė, V., Čygas, D., Ratkevičiūtè, K., \& Peltola, H. (2012). Safety ranking of the Lithuanian road network of national significance. The Baltic Journal of Road and Bridge Engineering, 7(2), 129-136. http://dx.doi.org/10.3846/bjrbe.2012.18

Ng, J., \& Sayed, T. (2004). Effect of geometric design consistency on road safety. Canadian Journal of Civil Engineering, 31(2), 218-227.

Ottensen, J. L., \& Krammes, R. A. (2000). Speed Profile Model for Design-Consistency Evaluation Procedure in the United States. Transportation Research Record: Journal of the Transportation Research Record, 1701, 76-85.

Polus, A., Fitzpatrick, K., \& Fambro, D. B. (2000). Predicting Operating Speeds on Tangent Sections of Two-Lane Rural Highways. Transportation Research Record: Journal of the Transportation Research Record, 173, 50-57. 